\title{
Aktivitas Makan Monyet Ekor Panjang (Macaca fascicularis) di Bumi Perkemahan Pramuka, Cibubur, Jakarta
}

\author{
Feeding Activities of Long-tailed Macaques (Macaca fascicularis) in Bumi Perkemahan \\ Pramuka, Cibubur, Jakarta \\ Hilda Farida ${ }^{1}$, Dyah Perwitasari-Farajallah ${ }^{1,2, *}$, dan Sri Sudarmiyati Tjitrosoedirdjo ${ }^{1,3}$ \\ ${ }^{1}$ Departemen Biologi, FMIPA-IPB Gd. FAPET Wing 1 Level 5, Kampus IPB Darmaga, Bogor 16680 \\ ${ }^{2}$ Pusat Studi Satwa Primata (PSSP), LPPM-IPB, Jl. Lodaya II/5, Bogor 16151 \\ ${ }^{3}$ SEAMEO BIOTROP, Jl. Raya Tajur Km. 6 PO BOX 116 Bogor 16134 \\ E-mail:witafar@ipb.ac.id,witafar@yahoo.com *Penulis untuk korespondensi
}

\begin{abstract}
Long-tailed macaque (Macaca fascicularis) is one of the non human primates which is widely distributed. Long-tailed macaques live in a group consisted of multimales and multifemales. The group size was determined by predator, food resources, and foraging efficiency. Bumi Perkemahan Pramuka Cibubur is a habitat for long-tailed macaques. This place is a camp area and tourism site, which is predominated by akasia (Acacia auriculiformis). This research is aimed to study feeding activity of long-tailed macaque in Bumi Perkemahan Pramuka, Cibubur, Jakarta. Methods used in this research were habituation, census, ad libitum sampling, focal animal sampling, and scan sampling. The identification of food items was carried out by means of direct observation, interview, specimen collection, and identification of plant species. Feeding activities of long-tailed macaques constituted $9.01 \%$ of the total daily activities. Food consumed consists of natural and non natural food. Natural food items were leaf buds of awi tali (Gigantochloa apus) 34.76\%, jukut pait (Axonopus compressus) $22.61 \%$, and fig (Ficus benjamina) $\mathbf{7 . 1 5 \%}$, respectively. Furthermore, non natural food items were food leftovers of visitors $\mathbf{2 9 . 0 0 \%}$ and peanuts $\mathbf{1 5 . 5 2 \%}$, respectively. In general, natural food $\mathbf{( 7 4 . 0 2 \% )}$ was consumed more frequent than those of non natural food $(\mathbf{2 5 . 9 8 \%})$.
\end{abstract}

Key words: Long-tailed macaque, feeding activities, Bumi Perkemahan Pramuka, Jakarta

Abstrak

Monyet ekor panjang (Macaca fascicularis) merupakan jenis primata bukan manusia yang penyebarannya sangat luas. Monyet ekor panjang hidup dalam kelompok yang terdiri dari banyak jantan dan banyak betina. Jumlah individu setiap kelompok ditentukan oleh predator, pertahanan terhadap sumber makanan, dan keefisienan dalam aktivitas mencari makan. Bumi Perkemahan Pramuka Cibubur merupakan areal perkemahan dan objek wisata yang didominasi oleh tumbuhan akasia (Acacia auriculiformis). Tujuan penelitian ini adalah untuk mengetahui aktivitas makan monyet ekor panjang di Bumi Perkemahan Pramuka Cibubur, Jakarta. Metode yang digunakan adalah habituasi, sensus, ad libitum sampling, focal animal sampling, dan scan sampling. Identifikasi jenis makanan yang dikonsumsi dilakukan dengan cara pengamatan langsung, wawancara, pengambilan spesimen, dan identifikasi jenis tumbuhan. Aktivitas makan monyet ekor panjang sebesar $9,01 \%$ dari total aktivitas harian. Makanan yang dikonsumsi berasal dari alam dan pengunjung (non-alam). Jenis makanan alami yang banyak dikonsumsi adalah tunas daun awi tali (Gigantochloa apus) 34,76\%, jukut pait (Axonopus compressus) 22,61\%, dan buah beringin (Ficus benjamina) 7,15\%. Jenis makanan dari pengunjung (non alami) yang banyak dikonsumsi adalah makanan sisa pengunjung $29,00 \%$ dan kacang $15,52 \%$. Secara keseluruhan, makanan alami lebih banyak dikonsumsi $\mathbf{7 4 , 0 2 \% )}$ daripada makanan non alami $(\mathbf{2 5 , 9 8 \%})$ dari total makanan yang dikonsumsi.

Kata kunci: Monyet ekor panjang, aktivitas makan, Bumi Perkemahan Pramuka, Jakarta 


\section{Pendahuluan}

Monyet ekor panjang (Macaca fascicularis) termasuk dalam Ordo Primata, Subordo Anthropoidea, Infraordo Catarrhini, Famili Cercopithecidae, dan Genus Macaca (Dolhinow dan Fuentes, 1999). Monyet ini memiliki tingkat adaptasi yang tinggi dan daerah penyebaran yang luas. Monyet ekor panjang tersebar di seluruh Asia Tenggara bahkan habitatnya berdekatan dengan permukiman manusia (Wheatley, 1980).

Monyet ekor panjang bersifat sosial dan hidup dalam kelompok yang terdiri atas banyak jantan dan banyak betina (multi males-multi females) dengan jumlah 20-50 individu (Bercovitch dan Huffman, 1999). Jumlah individu setiap kelompok ditentukan oleh predator, pertahanan terhadap sumber makanan, dan efisiensi dalam aktivitas mencari makan (McFarland, 1993).

Monyet biasanya mengambil makanan dengan kedua tangannya atau langsung dengan giginya (Wheatley, 1980). Dalam keadaan tergesa-gesa, monyet langsung mengisi kantong pipinya. Apabila keadaan sudah tenang dan nyaman, makanan dikeluarkan kembali untuk dikunyah dan ditelan. Monyet senang menguasai pakan sebanyak-banyaknya walaupun tidak mampu menghabiskannya. Hal ini berhubungan dengan keinginan untuk menunjukkan kekuatan terhadap monyet lain yang akan mengakibatkan perkelahian monyet (Putra et al., 2000).

Di lingkungan alaminya, monyet bersifat frugivor dengan pakan utamanya berupa buah (Cowlishaw dan Dunbar, 2000). Kriteria buah yang dipilih oleh monyet biasanya dilihat berdasarkan warna, bau, berat buah, dan kandungan nutrisi (Gautier-Hion, 1988). Selain buah, jenis makanan yang biasa dikonsumsi oleh monyet adalah daun, umbi, bunga (Hasanbahri et al., 1996), biji, dan serangga (Hadi et al., 2007).

Bumi Perkemahan Pramuka Cibubur merupakan areal perkemahan dan objek wisata yang terletak pada ketinggian $94 \mathrm{~m}$ di atas permukaan laut (dpl) dengan luas wilayah 210 ha. Hutan sekunder yang berada di Bumi Perkemahan Pramuka Cibubur didominasi oleh tumbuhan akasia (Acacia auriculiformis).

Penelitian ini bertujuan mengetahui aktivitas makan monyet ekor panjang ( $M$. fascicularis) di Bumi Perkemahan Pramuka Cibubur karena terbatasnya informasi mengenai monyet ekor panjang di tempat tersebut. Di samping itu penelitian ini juga bertujuan mengetahui ketersediaan pakan bagi kelangsungan hidup monyet.

\section{Metode Penelitian}

Penelitian dilaksanakan mulai bulan Februari hingga Juli 2008 di Bumi Perkemahan Pramuka Cibubur. Objek penelitian yang digunakan ialah monyet kelompok Depan dengan jumlah 45 individu dari total individu sebanyak 49 individu (survei tanggal 14 Juli 2008). Selain monyet ekor panjang, terdapat satu ekor beruk ( $M$. nemestrina) yang hidup dalam kelompok Depan. Total objek penelitian yang digunakan ialah 46 individu.

\section{Habituasi}

Proses untuk membiasakan hewan terhadap kehadiran pengamat sehingga pengamatan lebih mudah dilakukan. Setelah itu, dilakukan identifikasi dengan cara memberi nama tiap individu berdasarkan ciri-ciri fisik seperti raut muka, warna rambut, ukuran tubuh, bentuk tubuh, atau cacat pada tubuh. Proses habituasi dilakukan sebelum melakukan pengambilan data penelitian.

\section{Sensus}

Sensus dilakukan dengan menghitung jumlah individu ketika melakukan migrasi untuk mencari makan. Hal ini dilakukan untuk mengetahui jumlah individu pada saat awal, selama, dan akhir penelitian.

\section{Ad Libitum Sampling}

Pengamat mencatat sebanyak mungkin tingkah laku individu dalam suatu kelompok. Ad libitum sampling dilakukan untuk mengumpulkan data aktivitas harian yang dilakukan oleh individu sehingga hasil yang diperoleh berupa durasi dan frekuensi tingkah laku yang teramati selama pengamatan (Martin dan Bateson, 1993).

\section{Focal Animal Sampling}

Pengamat mengamati tingkah laku dari individu tertentu atau individu fokus yang 
pertama kali terlihat dalam suatu kelompok (Martin dan Bateson, 1993). Metode ini untuk mengamati individu fokus secara terus menerus. Focal animal sampling digunakan untuk mengumpulkan data aktivitas makan yang dilakukan oleh individu tertentu selama interval waktu 10 menit, sehingga diperoleh durasi tingkah laku yang muncul selama pengamatan.

\section{Scan Sampling}

Scan sampling dilakukan untuk mengamati tingkah laku makan individu yang pertama kali terlihat dalam interval waktu yang telah ditentukan. Interval waktu yang digunakan adalah satu menit. Hasil yang diperoleh berupa frekuensi tingkah laku makan yang muncul pertama kali selama pengamatan dalam interval waktu satu menit (Martin dan Bateson, 1993).

\section{Identifikasi Tumbuhan Pakan}

Pertama mencatat tumbuhan yang dikonsumsi monyet, kemudian melakukan wawancara dengan pegawai Bumi Perkemahan Pramuka Cibubur untuk mengetahui nama lokal tumbuhan. Pengambilan spesimen tumbuhan untuk identifikasi dengan cara mencocokkan spesimen yang dikoleksi dengan gambar-gambar yang ada di buku Heyne, 1987; Sastrapradja dan Afriastini, 1980; Duistermaat, 2005; dan Boo et al., 2003.

\section{Hasil dan Pembahasan}

\section{Jumlah Individu dan Komposisi Individu dalam Kelompok}

Bumi Perkemahan Pramuka Cibubur dihuni oleh 3 kelompok monyet ekor panjang, yaitu kelompok Depan, kelompok Belakang, dan kelompok Arboretum. Pada saat survei pertama tanggal 19 Maret 2008 kelompok Depan berjumlah 50 individu dan pada saat survei terakhir tanggal 14 Juli 2008 berjumlah 49 individu. Survei dilakukan sebanyak 5 kali selama penelitian. Kelompok Belakang yang teramati berjumlah 15 individu dan kelompok Arboretum berjumlah 15 individu (survei tanggal 14 Juni 2008). Metode survei yang dilakukan adalah dengan menghitung jumlah individu ketika melakukan migrasi untuk mencari makan. Survei dilakukan untuk mengetahui jumlah individu pada saat awal, selama, dan akhir penelitian.

Jumlah individu yang digunakan dalam penelitian ini adalah 46 individu dengan komposisi 6 jantan dewasa, 13 betina dewasa, 5 jantan muda, 6 betina muda, 13 juvenil, dan 3 bayi. Individu dengan kualitas tertentu dan lebih unggul daripada individu lain disebut individu dominan (Ray, 1999). Monyet yang dominan menempati urutan hierarki paling atas, sedangkan yang kurang dominan menempati urutan hierarki yang lebih rendah. Pada umumnya, individu jantan lebih dominan dibandingkan dengan individu betina (Napier dan Napier, 1985).

Waktu makan mempunyai pola berdasarkan hierarki. Individu berhierarki tinggi mempunyai peluang yang lebih besar dalam mendapatkan makanan dibandingkan dengan individu berhierarki rendah (Tabel 1). Juvenil monyet rhesus ( $M$. mulatta) dari induk berhierarki tinggi akan lebih mudah mendapatkan makanan dibandingkan juvenil dari induk berhierarki rendah (Peláez et al., 2000). Hierarki sosial ditentukan dengan cara mengamati monyet ketika melakukan aktivitas makan, kawin, menelisik (grooming), dan agresi. Monyet dengan urutan hierarki sosial atas akan makan terlebih dahulu, kemudian diikuti monyet lain sesuai dengan urutan hierarki. Selain itu, monyet yang berada pada hierarki sosial atas akan banyak mempunyai peluang melakukan aktivitas kawin dengan banyak betina dan lebih sering melakukan agresi. Pada saat melakukan aktivitas menelisik, monyet dengan urutan hierarki sosial atas lebih sering menjadi objek dibandingkan menjadi subjek.

\section{Aktivitas Makan}

Aktivitas makan monyet kelompok Depan banyak terjadi pada pagi hari (pukul 06.00-10.00) dan sore hari (pukul 15.00-17.45), serta sedikit pada siang hari (pukul 13.00-14.00). Pola tersebut terjadi jika cuaca normal, tetapi jika hujan dan angin kencang aktivitas makan akan menurun (Tabel 2). Aktivitas makan monyet ekor panjang selama pengamatan bulan Maret-Juli sebesar $9,01 \%$ dari total aktivitas harian kelompok tersebut (Tabel 3).

Total jumlah aktivitas makan diperoleh melalui pengambilan data dengan metode ad 
libitum sampling, focal animal sampling, dan scan sampling. Aktivitas makan yang rendah disebabkan oleh ketersediaan pakan tidak mencukupi dan periode penelitian yang dilakukan pada saat memasuki musim kemarau. Bila lingkungan tidak dapat mencukupi kebutuhan pakan monyet, monyet akan lebih banyak bergerak (Pombo, 2004).

Pagi sampai siang hari monyet berada di sekitar lapangan utama dan kafetaria. Aktivitas makan banyak terjadi di sekitar tepi lapangan yang ditumbuhi rerumputan seperti jukut pait (Axonopus compressus). Jukut pait merupakan salah satu sumber pakan monyet. Pada sore hari kelompok ini akan berada di tepi jalan raya Cibubur untuk melanjutkan kembali aktivitas makan yang berasal dari alam dan pengunjung.
Aktivitas makan monyet kelompok Pancalikan dengan jumlah 54 individu di Cagar Budaya Ciung Wanara sebesar 21,91\% dari total aktivitas harian (Rahayu, 2007). Aktivitas makan lebih banyak dilakukan di dalam hutan untuk mendapatkan sumber pakan berupa buah karena tunas awi tali mulai mengering pada saat musim kemarau. Menurut Yudanegara (2006), aktivitas makan kelompok Pancalikan yang teramati selama Mei-Juni 2005 sebesar 20,72\%. Aktivitas makan yang tinggi disebabkan penelitian dilakukan pada saat pertengahan musim hujan dan musim liburan, sehingga makanan yang berasal dari alam dan pengunjung masih cukup melimpah.

Tabel 1. Hierarki sosial sebagian individu (berupa inisial pemberian nama).

\begin{tabular}{ccc}
\hline \hline Hierarki Sosial & Individu Jantan Dewasa & Individu Betina Dewasa \\
\hline \hline Alfa & $\mathrm{ky}$ & $\mathrm{agl}$ \\
Beta & $\mathrm{adk}$ & $\mathrm{rsa}, \mathrm{nn} *$ \\
Gama & $\mathrm{ig}$ & $\mathrm{mm}, \mathrm{cnt}, \mathrm{bnn} *$ \\
Teta & $\mathrm{rb}, \mathrm{asp} *$ & $\mathrm{mps}, \mathrm{pn}, \mathrm{lla} *$ \\
\hline \hline
\end{tabular}

Keterangan $*=$ individu berada pada hierarki sosial yang sederajat.

Tabel 2. Pengaruh hari hujan terhadap aktivitas makan.

\begin{tabular}{cccc}
\hline \hline Bulan & Hari Hujan & Frekuensi (scan) & Waktu Pengamatan (hari) \\
\hline \hline Maret & 1 & 435 & 8 \\
April & 6 & 2206 & 20 \\
Mei & 1 & 485 & 17 \\
Juni & - & 481 & 17 \\
Juli & - & 189 & 14 \\
\hline Total & $\mathbf{8}$ & $\mathbf{3 7 9 6}$ & $\mathbf{7 6}$ \\
\hline \hline
\end{tabular}

Tabel 3. Persentase aktivitas harian monyet ekor panjang selama bulan Maret-Juli 2008.

\begin{tabular}{lcc}
\hline \hline \multicolumn{1}{c}{ Aktivitas } & Total Jumlah Aktivitas (kali) & Persentase (\%) \\
\hline \hline Bergerak & 25968 & 42,71 \\
Diam atau istirahat & 22714 & 37,35 \\
Makan & $\mathbf{5 4 8 0}$ & $\mathbf{9 , 0 1}$ \\
Bermain & 1919 & 3,16 \\
Allogrooming (menelisik yang dilakukan berpasangan) & 1794 & 2,95 \\
Autogrooming (menelisik yang dilakukan sendiri) & 835 & 1,37 \\
Mounting (kawin) & 590 & 0,97 \\
Agonistik (perkelahian) & 522 & 0,86 \\
Presenting (pengangkatan ekor yang dilakukan oleh betina) & 484 & 0,79 \\
Inspeksi (pemeriksaan alat kelamin betina oleh jantan) & 253 & 0,42 \\
Minum & 98 & 0,16 \\
Alarm call (sinyal peringatan) & 80 & 0,13 \\
Non-copulatory mounting (penaikan tanpa kopulasi) & 71 & 0,12 \\
\hline \hline
\end{tabular}


Crockett dan Wilson (1980), menyatakan bahwa monyet ekor panjang di Sumatera yang merupakan frugivor dan omnivor melakukan aktivitas diam sebesar 19,8\%, 18,8\% waktunya untuk makan, $11,1 \%$ untuk bergerak, $6,3 \%$ untuk berlari, dan $44 \%$ untuk aktivitas lainnya. Liontailed monkeys (M. silenus) di India menghabiskan sekitar 54,5\% waktunya untuk aktivitas makan, $27 \%$ untuk beristirahat, $15 \%$ untuk bergerak, dan 3,5\% untuk aktivitas sosial. $M$. silenus merupakan frugivor dan insektivor dengan memakan buah, serangga, siput, dan telur burung (Kurup dan Kumar, 1993).

Aktivitas makan kelompok Depan melalui metode scan sampling diketahui bahwa aktivitas makan lebih banyak dilakukan oleh individu dewasa (3212 scan atau 85\%) daripada juvenil (584 scan atau 15\%). Yudanegara (2006), menyatakan bahwa aktivitas makan kelompok Pancalikan selama Mei-Juni 2005 lebih banyak dilakukan oleh individu dewasa sebesar $57,53 \%$ dibandingkan juvenil sebesar $42,47 \%$. Aktivitas makan kelompok Pancalikan periode Juni-Agustus 2006 lebih banyak dilakukan oleh individu dewasa (3159 scan atau $71 \%)$ dibandingkan juvenil (1290 scan atau 29\%) (Rahayu, 2007).

\section{Jenis Makanan}

Monyet ekor panjang mengkonsumsi dua jenis makanan yaitu makanan alami dan makanan yang berasal dari pengunjung (non alami). Makanan alami yang banyak dikonsumsi adalah tunas daun awi tali (Gigantochloa apus) $34,76 \%$, jukut pait (A. compressus) 22,61\%, dan buah beringin (Ficus benjamina) $7,15 \%$ dari total makanan alami yang dikonsumsi. Jenis makanan non alami yang banyak dikonsumsi yaitu sisa pengunjung $29,00 \%$ dan kacang $15,52 \%$ dari total makanan non alami yang dikonsumsi. Secara keseluruhan, makanan alami lebih banyak dikonsumsi (4056 kali atau $74,02 \%$ ) daripada makanan non alami (1424 kali atau $25,98 \%$ ). Periode penelitian dilakukan pada peralihan musim hujan ke musim kemarau (Mei-Juni). Tunas daun awi tali banyak dikonsumsi pada bulan April dan Mei, jukut pait pada bulan Maret dan April, sedangkan buah banyak dikonsumsi pada bulan April dan Juni (Gambar 1). Jenis tumbuhan buah yang banyak dikonsumsi antara lain beringin, kersen (Muntingia calabura) 3,30\%, dan jambu biji (Psidium guajava) 1,63\%. Tumbuhan akasia yang merupakan tumbuhan dominan hanya dikonsumsi sebesar 4,34\%.

Selama bulan Maret-Juli monyet lebih banyak mengonsumsi daun daripada mengkonsumsi buah, sehingga lebih bersifat foliovor (Gambar 2). Sifat foliovor juga ditemukan pada monyet kelompok Pancalikan di Cagar Budaya Ciung Wanara yang lebih banyak mengkonsumsi tunas daun awi tali sebesar $70 \%$ daripada mengkonsumsi buah (Yudanegara, 2006).

Daun-daunan merupakan makanan penting bagi monyet Jepang ( $M$. fuscata) yang berada di dataran tinggi, sedangkan bagi $M$. fuscata yang berada di dataran rendah daun merupakan sumber makanan kedua setelah buah dan biji (Hanya et al., 2003). Lebih jauh lagi, $M$. fuscata di Yakushima mengonsumsi daun tua $45 \%$, bunga $15 \%$, jamur $14 \%$, buah $13 \%$, dan biji 4\% (Hanya, 2004). Sementara itu, tumbuhan jenis Ficus dan Syzygium merupakan sumber pakan bagi monyet di habitat hutan jati. Bagian dari tumbuhan yang paling disukai adalah buah, daun, dan umbi (Hasanbahri et al., 1996).

Gangguan pada habitat monyet menyebabkan kontak dengan manusia menjadi intensif. Hal ini mengakibatkan perubahan tingkah laku makan sehingga monyet akan mengeksploitasi sumber makanan dan akan bersifat omnivor (Hadi et al., 2007). Makanan yang berasal dari pengunjung lebih mudah didapat, memiliki nilai kalori yang lebih tinggi, dan bersifat temporer (Wheatley, 1989).

\section{Durasi Makan}

Waktu yang dibutuhkan individu juvenil untuk makan lebih lama dibandingkan dengan dewasa. Durasi makan untuk individu dewasa berkisar antara 1-10 menit, sedangkan juvenil memerlukan waktu antara 1-34 menit. Menurut Hanya (2003), aktivitas makan juvenil $M$. fuscata lebih sedikit, karena waktu makan juvenil lebih lama daripada dewasa. Juvenil perlu melindungi diri dari predator pada saat mencari makan dan belum adanya pengalaman untuk mencari sumber makanan. 


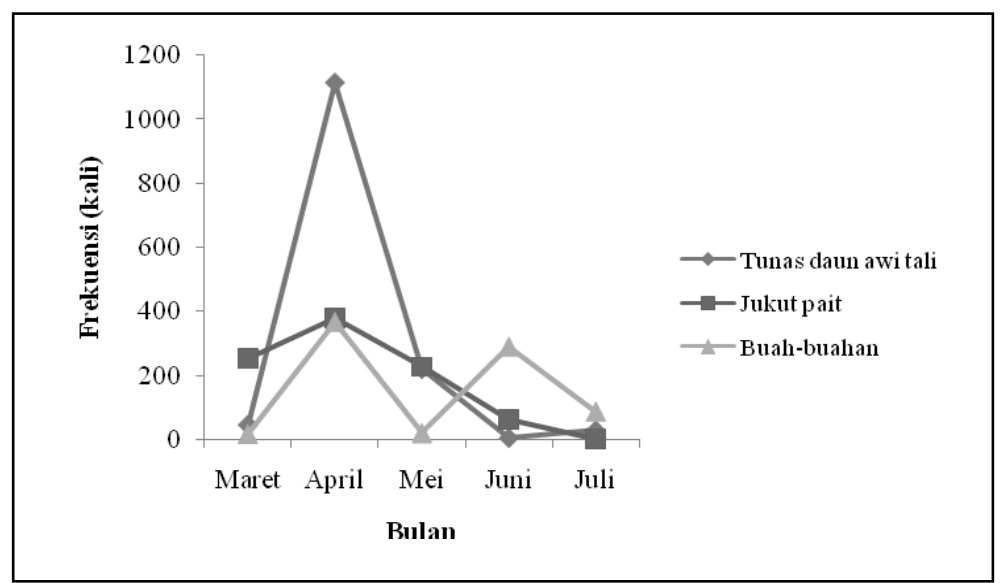

Gambar 1. Makanan alami yang banyak dikonsumsi monyet ekor panjang selama Maret-Juli.

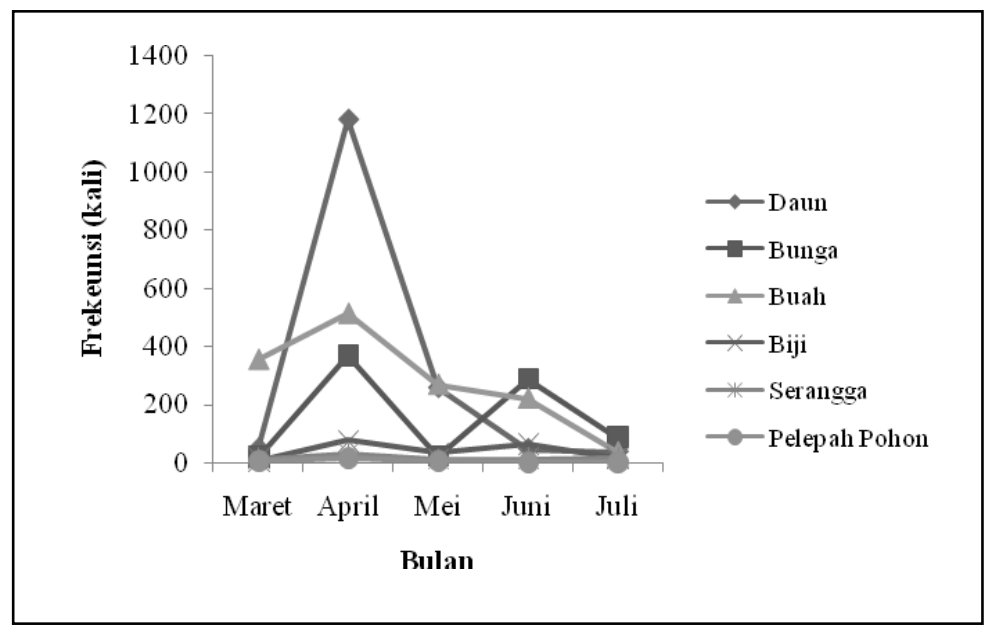

Gambar 2. Jenis makanan yang dikonsumsi monyet ekor panjang selama Maret-Juli.

\section{Simpulan dan Saran}

\section{Simpulan}

Aktivitas makan monyet ekor panjang di Bumi Perkemahan Pramuka Cibubur sebesar $9,01 \%$ dari total aktivitas harian. Aktivitas makan lebih banyak dilakukan individu dewasa dibandingkan juvenil. Selama bulan Maret-Juli monyet lebih banyak mengkonsumsi daun daripada mengonsumsi buah, sehingga dapat dikatakan lebih bersifat foliovor. Secara keseluruhan, makanan alami lebih banyak dikonsumsi (4056 kali atau 74,02\%) daripada makanan non alami (1424 kali atau 25,98\%). Makanan alami yang banyak dikonsumsi adalah tunas daun awi tali (Gigantochloa apus).

\section{Saran}

Penelitian lanjutan pada kelompok lain untuk membandingkan aktivitas makan dan keanekaragaman jenis makanan yang dikonsumsi monyet ekor panjang di Bumi Perkemahan Pramuka Cibubur. Penelitian pada musim hujan perlu dilakukan untuk membandingkan aktivitas tiap musim.

\section{Ucapan Terima Kasih}

Ucapan terima kasih penulis sampaikan kepada seluruh staf dan karyawan Bumi Perkemahan Pramuka Cibubur atas sarana, prasarana dan bantuannya selama penulis melaksanakan penelitian. 


\section{Daftar Pustaka}

Bercovitch, F.B. dan Huffman, M.A. 1999. The Macaques. In: Dolhinow, P., Fuentes, A., (Eds.). The Non Human Primates. California: Mayfield Publishing.

Boo, C.H., Omar-Hor, K. dan Lin, O.Y.C. 2003. 1001 Garden Plants in Singapore. Singapore: National Parks Board.

Cowlishaw, G. dan Dunbar, R. 2000. Primate Conservation Biology. Chicago: Univ Chicago Pr.

Crockett, C.M. dan Wilson, W.L. 1980. The Ecological Separation of Macaca nemestrina and Macaca fascicularis in Sumatera. In: Lindburg, D.E. editor. The Macaque: Studies in Ecology, Behaviour and Evolution. Pp 148-181. New York: Van Nostrand Reinhold.

Dolhinow, P. dan Fuentes, A. 1999. The Non Human Primates. California: Mayfield Publishing.

Duistermaat, H. 2005. Field to the Grasses of Singapore (Excluding the Bamboos). Singapore: National Parks Board.

Gautier-Hion, A. 1988. The Diet and Dietary Habits of Forest Guenons. In: Gautier-Hion, A., Bouliere, F. and Gautier, J.P. (Eds.). A Primate Radiation: Evolutionary Biology of the African Guenons. Pp. 257-283. London: Cambridge Univ Pr.

Hadi, I., Suryobroto, B. dan Perwitasari-Farajallah, D. 2007. Food Preference of Semi-Provisioned Macaques Based on Feeding Duration and Foraging Party Size. Hayati, 14 (1): 13-17.

Hanya, G. 2003. Age Differences in Food Intake and Dietary Selection of Wild Male JAPANESE Macaque. Primates, 44 (1): 333-339.

Hanya, G. 2004. Diet of a Japanese macaque troop in the coniferous forest of Yakushima. Int J. Primatol 25 (1): 55-68.

Hanya, G., Noma, N. dan Agetsuma, N. 2003. Altitudinal and Seasonal Variation in the Diet of Japanese Macaques in Yakushima. Primates, 44 (4): 51-59.

Hasanbahri, S., Djuwantoko dan Ngariana, I.N. 1996. Komposisi Jenis Tumbuhan Pakan Kera Ekor Panjang (Macaca fascicularis) di Habitat Hutan Jati. Biota, 1 (2): 1-8.

Heyne, K. 1987. Tumbuhan Berguna Indonesia volume IIV. Jakarta: Badan Penelitian dan Pengembangan Kehutanan Departeman Kehutanan.

Kurup, G.U. dan Kumar, A. 1993. Time Budget and Activity Patterns of the Lion-Tailed Macaque (Macaca silenus). Int J. Primatol, 14 (1): 27-39.
Martin, P. dan Bateson, P. 1993. Measuring Behaviour: An Introduction Guide. Ed ke-2. London: Cambridge Univ Pr.

McFarland, D. 1993. Animal Behaviour. Ed ke-2. Singapore: Longman.

Napier, J.R. dan Napier, P.H. 1985. The Natural History of the Primates. Cambridge: The MIT Pr.

Peláez, F., Gil-Burman, C. dan Sánchez, S. 2000. Feeding Tactics in Juvenile Rhesus Monkeys (Macaca mulatta). Am J. Primatol, 51 (1): 147-152.

Pombo, R.A.E.R. 2004. Daerah Jelajah, Perilaku, dan Pakan Macaca tonkeana di Taman Nasional Lore Lindu, Sulawesi Tengah. Tesis. Program Pascasarjana, Institut Pertanian Bogor.

Putra Arta, I.G.A., Fuentes, A., Suaryana, K.G. dan Rompis, A.L.T. 2000. Perilaku Makan Monyet Ekor Panjang (Macaca fascicularis) di Wenara Wana, Pedangtegal, Ubud, Bali. Konservasi Satwa Primata: Tinjauan Ekologi, Sosial Ekonomi, dan Medis dalam Pengembangan Ilmu Pengetahuan dan Teknologi. Pros. Sem. Primatologi Indonesia, Yogyakarta 7 September 2000. Universitas Gadjah Mada Yogyakarta.

Rahayu, R. 2007. Aktivitas Makan Monyet Ekor Panjang (Macaca fascicularis) Kelompok Pancalikan Periode Juni-Agustus di Cagar Budaya Ciung Wanara Ciamis, Jawa Barat. Skripsi. Institut Pertanian Bogor.

Ray, E. 1999. The Macaques. In: Dolhinow, P., Fuentes, A. (Eds.). The Non Human Primates. California: Mayfield Publishing.

Sastrapradja, S. dan Afriastini, J.J. 1980. Jenis Rumput Dataran Rendah. Bogor: Lembaga Biologi Nasional-LIPI.

Wheatley, B.P. 1980. Feeding and Ranging of East Bornean Macaca fascicularis. In: Lindburg, D.E. (Eds) The Macaque: Studies in Ecology, Behaviour and Evolution. Pp. 257-283. New York: Van Nostrand Reinhold.

Wheatley, B.P. 1989. Diet of Balinese Temple Monkeys Macaca fascicularis. Kyoto University Overseas Research, Report at Studies on Asian Non-Human Primates no 7.

Yudanegara, A. 2006. Aktivitas Makan Monyet Ekor Panjang (Macaca fascicularis) Kelompok Pancalikan di Situs Ciung Wanara, Ciamis, Jawa Barat. Skripsi. Bogor: Institut Pertanian Bogor. 